\title{
An Exploratory Study of the Emerging Role of Electronic Intermediaries
}

\author{
Joseph P. Bailey ${ }^{*}$ and Yannis Bakos** \\ International Journal of Electronic Commerce, Volume 1, No. 3, Spring 1997, pp. 7-20.
}

\begin{abstract}
It is often argued that as electronic markets lower the cost of market transactions, traditional roles for intermediaries will be eliminated, leading to "disintermediation." We discuss the findings of an exploratory study of intermediaries in electronic markets, which suggest that markets do not necessarily become disintermediated as they become facilitated by information technology. We explore thirteen case studies of firms participating in electronic commerce and find evidence of certain new emerging roles for electronic intermediaries, including: aggregating, matching suppliers and customers, providing trust, and providing inter-organizational market information. Two specific examples are discussed in greater detail to illustrate an unsuccessful strategy for electronic intermediation (BargainFinder) as well as a successful one (Firefly).
\end{abstract}

KEY WORDS AND PHRASES: electronic data interchange, electronic markets, intermediaries, Internet commerce.

Technology, Management and Policy, Massachusetts Institute of Technology; email: bailey@rpcp.mit.edu

** Center for Research in Information Technology and Organizations, Graduate School of Management, University of California, Irvine; email: bakos@ @ci.edu; web: http://www.gsm.uci.edu/ bakos 


\section{INTRODUCTION}

Technologies such as Electronic Data Interchange (EDI) over the Internet and sales over the World Wide Web are emerging as an important medium for market transactions. Firms and individuals increasingly participate in electronic commerce as customers, suppliers or intermediaries. Commercial web sites are established for a variety of reasons, including appealing to potential customers to form new relationships and communicating with current customers to strengthen existing relationships. The importance of such "electronic markets" will rapidly increase in the next few years, as public and private standards are established for information exchange and electronic commerce over the Internet.

Traditional physical markets are often brokered by intermediaries, or parties that facilitate market transactions by providing intermediation services. For instance, the owner of a shopping mall typically provides many intermediation services in the physical world, such as a physical infrastructure and management of the flow of customers visiting the mall. However, the value of these services may be reduced once the relationship moves to an electronic market. In particular, electronic markets do not require services related to the matching of customers and suppliers in the physical space. In fact, the information infrastructure may make it so easy to match customers and suppliers that the role of intermediaries may be reduced or even eliminated. This possibility was identified by Malone, Benjamin and Yates [13], and more recently has been termed "disintermediation" (e.g., see Gellman [10]).

While the possibility of disintermediation raises important questions about the impact of electronic markets on the role of intermediaries, there is a lack of data or empirical studies addressing this issue. Given the scarcity of relevant data, we want to share some preliminary evidence on this subject. The class projects in an MBA class on "Electronic Commerce and Marketing on the Internet" at the MIT Sloan School of Management provided us with detailed reports on thirteen electronic markets, which were selected to span both industrial (business-to-business) and consumer (business to consumer) settings in manufacturing and in services.

Interestingly, this survey suggests that Gellman's disintermediation hypothesis [10] may be only partially true: while some roles of traditional intermediaries may be diminished in electronic markets, new roles for intermediaries are emerging. While our informal data gathering cannot be used for formal hypothesis testing, the insights we gained may be helpful to other researchers in this area. Indeed, in a majority of the markets we surveyed we found that new roles emerge for electronic intermediaries that seem to outweigh any trend towards disintermediation. This finding suggests the need for theory development, rigorous data collection and formal empirical analysis to research the emerging role of electronic intermediaries. 


\section{ROLES OF MARKET INTERMEDIARIES}

Firms and markets can organize in a variety of structures. Malone, Yates, and Benjamin [13] discuss different types of "markets" and "hierarchies" as organizational structures that maximize efficiency in different economic settings. Certain organizational structures include firms or individuals that serve as intermediaries between customers and suppliers. But how do these intermediaries add value?

Several roles of intermediaries have been identified in the literature. For instance, Resnick, Zeckhauser, and Avery [15] suggest that brokers are important in markets because search costs, lack of privacy, incomplete information, contracting risk, and pricing are better managed through a broker. Malone, Yates, and Benjamin [13] define similar reasons to have intermediaries: reducing coordination costs, addressing problems of asset specificity, and promoting standardization. Williamson's transaction cost theory [17] builds on Coase [7] and offers a theory of firm boundaries by arguing that the cost of contracting, enforcing the contracts, and dealing with unforeseen circumstances varies depending on whether a market or a hierarchical structure is employed.

Thus four important roles of market intermediaries suggested by the literature are: ${ }^{1}$

(a) aggregate buyer demand or seller products to achieve economies of scale or scope $[8,15]$ and to reduce bargaining asymmetry [17];

(b) protect buyers and sellers from the opportunistic behavior of other participants in a market by becoming an agent of trust [17];

(c) facilitate the market by reducing operating costs $[13,15]$; and,

(d) match buyers and sellers [13, 15].

We now discuss in more detail the above four roles that intermediaries assume in the process of facilitating market transactions. In Section 4, we revisit these roles and we explore their evolution in electronic markets.

\section{Aggregation}

Instead of a situation where each customer will have to negotiate individually with an appropriate supplier, and each supplier will have to negotiate terms and fill the orders of individual customers, the intermediary can aggregate the demand of many customers or the products of many suppliers. Potential benefits include reducing transaction costs, taking

1 These roles are only identified to describe certain trends in electronic intermediation. They are not intended to form a taxonomy of the functions of an intermediary, and thus although they are distinct, they are not necessarily orthogonal or complete as a set. 
advantage of economies of scale, and reducing asymmetries in the bargaining power of customers and suppliers. Wholesalers and cooperatives provide examples of intermediaries that typically aggregate customer demands, whereas travel agencies sometimes aggregate products offered by hotels, airlines and ground transportation companies to provide landand-air packages.

\section{Trust}

Intermediaries may be able to prevent the parties to a market transaction from behaving opportunistically. Because of their long-term participation in the market, intermediaries have high incentives to ensure that market transactions are completed, and that each party involved - the supplier and customer - lives up to their end of the bargain. Since the parties to a transaction may need in the future to interact with the intermediary even if they never do business with each other again, the intermediary may be in a better position to prevent opportunistic behavior, compared to other market participants. Also, intermediaries are typically involved in many more transactions than any individual customer or supplier, and as a result may enjoy economies of scale in their investments in monitoring technology, or they may be able to better insure against certain transaction failures. Travel agents, for example, protect customers from the risk of carrier failure, a valuable service when purchasing tickets for travel on financially weak airlines.

\section{Facilitation}

Information transfer between organizations is costly, especially when it involves "implicit" or contextual knowledge that cannot be easily articulated. In these instances, an intermediary can facilitate the exchange of information by coordinating the process and translating the information that is sent between the supplier and the consumer. Intermediaries can also facilitate markets by reducing overall processing and coordination costs. For example, full connectivity in an disintermediated market with $m$ buyers and $n$ sellers would require each of the $m$ buyers to connect to all $n$ sellers, for a total number of $m n$ connections [13]. An intermediary, on the other hand, could collect full information about the sellers with $m$ inquiries, and pass that information to the buyers with $n$ additional transfers of information, for a total of $m+n$ transactions. In markets with many customers and/or suppliers, $m+n$ will be significantly smaller than $m n$, signifying that an intermediary may be able to reduce significantly the processing and coordination costs in a market. Finally, intermediaries can facilitate markets by providing associated services, such as processing of payments or handling of documents. Travel agents, for example, facilitate transactions by providing information on several travel alternatives, processing payments and printing tickets, invoices and itineraries.

\section{Matching}

The need of customers to locate an appropriate supplier and for suppliers to find appropriate customers can be accommodated by an intermediary that becomes a focal point for this 
match. Intermediaries might be better at this than customers and suppliers left on their own, for instance because intermediaries might be able to provide a price discovery mechanism or acquire better knowledge of the market demand and supply characteristics. Furthermore, since intermediaries participate in transactions with different customers, different suppliers, and potentially in different industries, intermediaries can analyze consumer preferences across products, suppliers and industries. Intermediaries can utilize this type of information in improving their ability to match customers and suppliers, or they may offer this marketing and customer demand information to suppliers. Travel agents, for example, routinely use their knowledge of customers' needs and the available travel options to select the best alternative for their customers.

The ability of an organization to perform well in the above four roles is central to its success as a market intermediary. The New York Stock Exchange, for example, has been very successful by excelling in providing trust (e.g., through its reputation, regulatory framework, and elimination of trading risk), in facilitating markets (e.g., through its ownership of the SIAC system for the settlement and clearing of transactions) and in matching buyers and sellers (e.g., through its specialist-based price discovery system). Yet, its relative neglect of the aggregation role has provided a niche for POSIT, an intermediary run by the International Trading Group that focuses on the trading of baskets of securities, which is the fastest growing off-exchange dealing system at the time of this writing.

\section{ELECTRONIC MARKETS}

An electronic market exists when a supplier provides goods and services to a customer in a transaction partially or fully automated by information technology. For example, Bakos [1] defines an electronic market system as an interorganizational information system that allows the participating buyers and sellers in some market to exchange information about prices and product offerings. Malone, Yates, and Benjamin [13, 14] discuss further the attributes that define an "electronic market." The increased use of electronic data interchange (EDI) to conduct business-to-business transactions, and the increasing use of the Internet for both business-to-business and business-to-consumer transactions, present new areas of research within the context of electronic markets. While EDI and the Internet have very different origins, they are the most ubiquitous infrastructures for electronic markets, and recently the boundary between them seems to be blurring.

EDI (Electronic Data Interchange) originated in the 1960s. Its intended purpose was to replace paper communication with electronic communication. This would increase the speed of communication and facilitate record keeping (e.g., there is no need for information from an invoice printed by one computer system to be retyped by the other party). Since then, EDI has grown to provide transaction standards for a wide range of electronic markets. Today, the growth rate of EDI is approximately $45 \%$ per year with more than $90 \%$ of the Fortune 1000 companies using EDI standards [12, p. 334]. While most EDI transactions are 
still sent over value added networks (VANs), the number of transactions over the Internet is rapidly increasing and poised to surpass VAN transactions before the end of the decade.

The Internet started with the ARPANET in the 1960s and has grown to support electronic markets even faster than EDI. ${ }^{2}$ As Clark [5] points out, the design philosophy of the Internet was not to reduce the transaction costs or support electronic markets, but to provide a robust heterogeneous distributed computing environment for applications that may not yet be developed. Only in the past few years has the Internet been transformed to improve security and privatize its infrastructure. Both of these developments have promoted electronic commerce applications over the Internet infrastructure. Aside from the EDI transactions, the Internet also provides a host of applications including electronic mail and the World Wide Web, which can support electronic markets.

Several authors in the literature, including Bakos [1], Clemons, Reddi and Row [6] and Malone, Yates and Benjamin [13] have pointed out that electronic markets are likely to have a major impact on the organization of economic activity and on the role of intermediaries in markets.

\section{MARKETS SURVEYED}

We obtained detailed reports on the strategy and intermediation characteristics of thirteen firms participating in thirteen electronic markets. These reports were in partial fulfillment of the required class projects in an MBA class on "Electronic Commerce and Marketing on the Internet" taught at the MIT Sloan School of Management. The reports also included the results of structured interviews with top-level managers at the studied firms. This data was examined to determine how intermediaries benefit participants in electronic markets by reducing transaction and coordination costs. The purpose for which information technology is adopted, the setting in which it is put to use and the process through which it is implemented, all determine what organizational changes will result from it, affecting, in turn, the emerging roles of electronic intermediaries.

Participants in the thirteen electronic markets surveyed were promised anonymity due to the proprietary nature of the information they were asked to disclose. These firms were selected to operate in markets for both physical goods and information goods. The physical goods intermediaries surveyed included industries in the service sector (retail) and in manufacturing (automotive). For these industries, intermediaries were surveyed in both the industrial (business-to-business) and the consumer (business to consumer) markets. In the information goods sector we were only able to identify intermediaries in business-to-

${ }^{2}$ While it is difficult to find a common metric to compare the two infrastructures, as of this writing the number of companies that are adding new Web sites to the Internet averages to approximately 73 per day [16]. 
consumer markets. Thus five types of intermediaries were surveyed, with 2-4 firms in each category. These categories are described below, with the number of corresponding firms surveyed in parentheses, and are shown in Table 1.

\begin{tabular}{|l|c|c|}
\hline & $\begin{array}{c}\text { Industrial (business-to- } \\
\text { business) }\end{array}$ & $\begin{array}{c}\text { Consumer (business-to- } \\
\text { consumer) }\end{array}$ \\
\hline Service (retail) & 2 & 3 \\
\hline $\begin{array}{l}\text { Manufacturing } \\
\text { (automotive) }\end{array}$ & 2 & 3 \\
\hline Information & none & 3 \\
\hline
\end{tabular}

Table 1. Types of Electronic Markets surveyed

\section{Retail - Business-to-Business (2)}

This category includes two electronic markets for products of low asset specificity with multiple suppliers and multiple customers. The amount of information necessary to describe these products is limited since both the customer and the supplier know the product and there is a high degree of standardization. This business-to-business retail market differs from the consumer retail market as transactions between customers and suppliers take place more frequently in the business-to-business market, and relationships last for longer periods of time. The technology employed in these markets was typically based on electronic data interchange (EDI) as EDI works well with highly standardized transactions between businesses that have an existing relationship.

\section{Retail - Business-to-Consumers (3)}

Similar to the retail business described above, transactions in this market involve goods with low asset specificity and high degree of standardization. However, these markets directly address consumers who are purchasing for personal use. The infrastructure of these markets was not based on EDI, and instead relied on Internet-based applications.

\section{Automotive - Business-to-Business (2)}

Two industrial (i.e., business-to-business) electronic markets were surveyed in the automotive parts industry. The products traded in these markets have a high degree of asset specificity as several car parts can only fit a single model. Relative to the retail sector, the set of possible business partners is smaller and their relationships are longer-term. The market infrastructure in these electronic markets was primarily based on EDI over VANs. 


\section{Automotive - Business-to-Consumers (3)}

Three electronic markets in the retail automotive sector were studied. As the firms investigated cater to individuals, the relationships are not as long-lived or as complex as in the case of the business-to-business markets, and they are characterized by relatively infrequent transactions.

\section{Information Goods - Business-to-Consumers (3)}

In the final category, we looked at three firms that do not sell physical goods or services, but they rather sell information. In these markets, the electronic market infrastructure not only can bring together a customer and a supplier, but it can also manipulate the information good changing its characteristics, and can serve as the distribution channel, delivering the good to the customer.

To assess the impact of electronic markets, the firms surveyed were asked to rate the importance of certain intermediation services in the corresponding electronic market, and to compare the importance of these services in the electronic market with their importance in the traditional physical market. Table 2 lists eight intermediation services that were examined this way, and their correspondence to the four roles of market intermediaries identified in Section 2.

\begin{tabular}{|l|c|c|}
\hline $\begin{array}{l}\text { Role of market } \\
\text { Intermediaries }\end{array}$ & $\begin{array}{c}\text { Physical-oriented } \\
\text { intermediation service }\end{array}$ & $\begin{array}{c}\text { Information-oriented } \\
\text { intermediation service }\end{array}$ \\
\hline Aggregation & $\begin{array}{c}\text { Combination of customer } \\
\text { orders in wholesale orders }\end{array}$ & $\begin{array}{c}\text { Provision of one-stop } \\
\text { shopping }\end{array}$ \\
\hline Trust & $\begin{array}{c}\text { Provide legal contracts to } \\
\text { govern market participation }\end{array}$ & $\begin{array}{c}\text { Provision of authentication } \\
\text { and secure communications }\end{array}$ \\
\hline Facilitation & $\begin{array}{c}\text { Provision of market-specific } \\
\text { infrastructure }\end{array}$ & $\begin{array}{c}\text { Exchange of messages } \\
\text { between customers and } \\
\text { suppliers }\end{array}$ \\
\hline Matching & $\begin{array}{c}\text { Provision of rich product } \\
\text { information }\end{array}$ & $\begin{array}{c}\text { Provision of marketing } \\
\text { information to suppliers }\end{array}$ \\
\hline
\end{tabular}

Table 2. Intermediation Services compared between traditional and Electronic Markets 


\section{INTERPRETATION}

Table 3 summarizes the relative importance of the intermediation services listed in Table 2, as affected by the move from traditional markets to electronic markets. For our sample of thirteen electronic markets, a "yes" indicates an increasing role of the corresponding intermediation service as we move from a physical market to an electronic market. A "no" indicates a stable or decreasing role, and a "maybe" indicates that the opinion of the respondents was divided. Table 3 is based on the self-reported assessments of the firms participating in the surveyed electronic markets, i.e., without comparing these characteristics to a matching control group of markets with traditional non-electronic intermediaries. While our sample is too small for formal empirical analysis, this information can still provide useful insights on the changing role of intermediaries.

\begin{tabular}{|c|c|c|c|c|c|c|c|c|}
\hline & \multicolumn{2}{|c|}{ Aggregation } & \multicolumn{2}{|c|}{ Trust } & \multicolumn{2}{|c|}{ Facilitation } & \multicolumn{2}{|c|}{ Matching } \\
\hline & 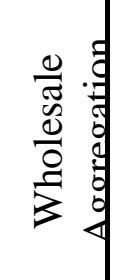 & 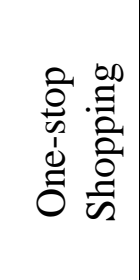 & 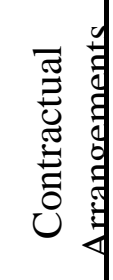 & 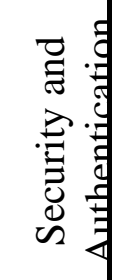 & 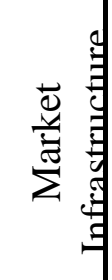 & 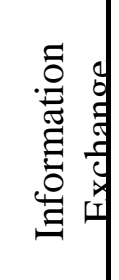 & 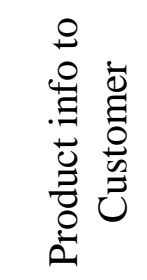 & 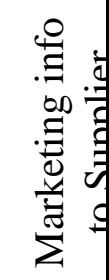 \\
\hline $\begin{array}{c}\text { Retail, } \\
\text { Business-to-Business }\end{array}$ & No & No & No & Yes & No & Yes & Maybe & Yes \\
\hline $\begin{array}{c}\text { Retail, } \\
\text { Business-to-Consumers }\end{array}$ & No & Maybe & No & Yes & No & Yes & Yes & Yes \\
\hline $\begin{array}{c}\text { Automotive, } \\
\text { Business-to-Business }\end{array}$ & No & No & No & Yes & No & Yes & No & No \\
\hline $\begin{array}{c}\text { Automotive, } \\
\text { Business-to-Consumers }\end{array}$ & No & Yes & No & Yes & No & Yes & Yes & No \\
\hline $\begin{array}{l}\text { Information Goods, } \\
\text { Business-to-Consumers }\end{array}$ & No & No & No & Yes & No & Yes & Yes & Yes \\
\hline
\end{tabular}

Table 3. Does the move to electronic markets increase the importance of these intermediation services?

\section{Aggregation}

As transactions move from a physical market to an electronic market, the need for an aggregating intermediary may diminish, as was the overall trend reported by our survey respondents. This may lead to disintermediation of the aggregation role of market intermediaries. For example, the reduced search costs in electronic markets may allow some customers to locate all product offerings they need without relying on the one-stop 
shopping and physical infrastructure of an intermediary. Alternatively, customers could use the Internet to self-organize in electronic communities that possess bargaining power in dealing with suppliers. Consistent with this, the firms surveyed in the retail and automotive sectors did not use an intermediary. Even though the pricing of the goods in these markets was non-linear (i.e., it allowed for quantity discounts), customers were able to receive better prices by working directly with the suppliers. Going through the electronic intermediaries resulted in intermediary charges that would negate the benefits from placing larger orders.

Although the markets we surveyed were consistent with disintermediation of the aggregator role of electronic intermediaries, the reduced coordination costs enabled by the market infrastructure may promote the emergence of intermediaries that increase customers' collective bargaining power, such as electronic cooperatives. Or, as search costs are reduced and geographic location becomes unimportant in selecting suppliers, the number of potential suppliers can increase dramatically. This can result in a very large number of potential interactions among product offerings, and the need will emerge for intermediaries that can offer complete solutions.

Finally, while many vendors are seeking to sell their goods directly via the World Wide Web, it is interesting to note that aggregating intermediaries have also found a role on the Internet. Some of the most successful have been firms such as America Online, Electric Library and the Microsoft Network, which resell digital information goods produced by other firms. However, their success is much less dependent on the traditional role of assembling a variety of sellers in one location. Instead, the emergence of electronic markets in digital information goods is reflective of a new class of opportunities for intermediaries acting as content aggregators.

Digital information goods, such as a news article, a digital image or a song, allow perfect copies to be created and distributed almost costlessly via the Internet. As shown by Bakos and Brynjolfsson [3], a strategy of selling a bundle of many distinct information goods for a single price often yields higher profits and greater efficiency than selling the same goods separately. In other words, the nature of information goods and the emergence of an electronic market infrastructure that allows their efficient distribution, create new roles for content aggregating intermediaries that will bundle large numbers of information goods.

\section{Trust}

All electronic market participants in our survey placed greater value on electronic authentication and security services in electronic markets, and indicated a relative decrease in their reliance on legal contracts. This reflects the fact that both the legal framework and the technological mechanisms for ensuring trust in electronic market transactions are not universal, and are still in their nascent stages. Consequently, participants in electronic markets are frequently concerned that it is possible to falsify electronic documents or create fraudulent electronic presence, which increases the importance of the trust role of electronic intermediaries, as is argued by Froomkin [9]. Even when technologies such as digital 
signatures become widely adopted and incorporated in the commercial legal framework, intermediaries will play an important role in providing the trust and security infrastructure. On the other hand, the need for intermediaries to act as providers of trust may decrease once an adequate legal framework for electronic commerce is in place.

In the business-to-business cases, trust was typically provided by the network provider, usually an EDI/value added network (VAN). The VAN provider ensures the trustworthiness of participants by screening them as they connect to the infrastructure. Part of this screening process includes the high fixed cost to join the infrastructure. Network providers can typically guarantee the security of transactions on the network, either because they own the network or because they have established security procedures in cooperation with the networks they interconnect with.

Among the surveyed firms, security was a more serious concern in the Internet-based electronic markets. Messages may get routed through networks over which the message originator has no control, and security requires the deployment of cryptographic technologies such as public key encryption, an area where few companies have adequate expertise. Thus the provision of trust services for Internet commerce is an important role for electronic intermediaries, and several firms are currently jockeying for position to establish themselves in that role.

\section{Facilitation}

The firms surveyed reported a reduced need for infrastructure-related facilitation services as they move from physical to electronic markets. Indeed, in an electronic market, suppliers and customers will typically agree to use a common electronic commerce infrastructure (e.g., EDI over a VAN or the Internet) so the value of a facilitator is reduced. In other words, the communications network and the standards for electronic commerce replace the intermediary as facilitator. This trend could lower the demand for intermediaries, and potentially lead to disintermediation.

Once a path to connect a supplier and a customer has been established, information transfer can take place without the need for an intermediary. However, most firms surveyed did not report this type of disintermediation in their markets: it seems that electronic markets create the need for increased exchange of information with other market participants, and this may discourage the bypassing of intermediaries. Naturally, as market participants become more proficient in taking advantage of the information infrastructure, bypassing of more intermediaries could take place in the future.

\section{Matching}

The emergence of electronic markets may substantially reduce search costs, as is proposed by Bakos $[1,2]$. The result of this trend for electronic market intermediation is ambiguous. On one hand lower search costs will reduce the importance of intermediaries by allowing 
buyers to search directly for appropriate suppliers, while on the other hand the overwhelming abundance of information offered by Internet-based market infrastructures may increase the need for intermediaries that can help to match customers and suppliers by filtering this information.

This ambivalence is reflected in our survey, with participants responding that matching suppliers and customers becomes more important in the business-to-consumer markets, but less important in the business-to-business markets. A substantial fraction of the businessto-business transactions involved firms that had worked together before, and thus there was no need to seek out new business partners. Transactions in the business-to-consumer electronic markets were characterized by lower frequency, and participants indicated that intermediaries could add value by providing market knowledge that helps match customers and suppliers.

The survey respondents also differed on their assessment of the ability of electronic intermediaries to provide marketing information. In an electronic market, this marketing information becomes more dynamic and easier to customize, so the intermediary can supply more accurate data. When marketing data is in digital form, manipulating data to understand the behavior of a particular customer or groups of customers is much easier.

\section{BARGAINFINDER AND FIREFLY}

To probe further the emerging roles of electronic intermediaries, we now discuss two firms that have followed different strategies for market intermediation in the retail music industry. These cases demonstrate that electronic intermediaries can be important in providing some services, while they may not be useful at filling certain functions associated with traditional intermediaries. It is thus important for intermediaries in electronic markets to identify a proper strategy that will be beneficial both to the participants in the electronic market and to the intermediaries themselves. Failure to do so may result in strategic failure for the electronic intermediary.

BargainFinder (http://bf.cstar.ac.com/bf/) was developed by Andersen Consulting and provides an intermediary that searches several compact disc (CD) stores on the World Wide Web. A customer types the title and artist of the CD he or she would like to purchase, and BargainFinder dispatches a price query agent to the different Web stores to help the customer compare prices. Since BargainFinder only provides users with price information, it promotes price competition among CD suppliers. The BargainFinder service is thus at odds with the incentives of suppliers in the CD market. Not surprisingly, as long as only a small fraction of CD buyers use BargainFinder, CD suppliers are resisting BargainFinder. At the time of this writing, the authors searched via BargainFinder for a popular CD that is easily available at a retail store. Of the eight Web stores the BargainFinder agent searched, only three reported back their prices, with the remaining five stores blocking the BargainFinder agent from searching their database. 
The second electronic market intermediary, Agents Inc. (http://www.agentsinc.com) has been much more successful, attracting more than one million users as of this writing. Their flagship product, Firefly, is as a matching intermediary. Firefly makes individualized recommendations for new music CD's based on a member's ratings for music he or she is familiar with. Using this system, a member can ask Firefly to recommend other music that he or she is not aware of, but can be expected to like. The same technology can be used in areas other than music, as well as to find other members with similar preferences in music or other areas. This "collaborative filter" is a powerful way for an intermediary to provide value to all users.

The relative success of Firefly when compared to BargainFinder may be explained by looking at customers' and suppliers' incentives for participation. In the case of Firefly, it is clear that exposing potential customers to new music can expand the market and increase sales. With BargainFinder, on the other hand, there is a disincentive for suppliers to disclose their prices since then they will have to compete solely based on price. These two electronic intermediaries demonstrate that providing value to both sides of the market is essential to avoid incentive compatibility problems. BargainFinder's role of matching customers and suppliers based on price does not meet this test. In contrast, the marketing information and matching intermediary roles of Firefly do add value, and thus Firefly has been successful.

\section{CONCLUDING REMARKS}

While some of the traditional roles of intermediaries may become less important as information technology facilitates communication between customers and suppliers, the need for intermediaries is not likely to be eliminated in the near future. Intermediaries in electronic markets are likely to assume important roles that will include aggregating information goods, providing trust relationships and ensuring the integrity of the market, matching customers and suppliers, and providing marketing information to suppliers.

Differences in the nature of electronic markets will affect the role of intermediaries. In markets such as consumer markets, characterized by a large number of products and infrequent purchases, the matching role of intermediaries will be more important. Markets with fewer suppliers and customers and frequent purchases, such as industrial markets in the automotive industry, will have less need for matching intermediaries. While businesses often have high repetition and strong relationships with their suppliers, consumers are more likely to express dissatisfaction with suppliers through "exit" rather than "voice" [11]. As a result, intermediaries in consumer-oriented electronic markets may help reduce the search space and introduce users to "communities of interest" for peer recommendations. Finally, intermediaries can provide marketing information that allows suppliers to tailor their products based on their marketing strategy and on their customers' needs. 
While both theory development and formal empirical research is needed to study the intermediation benefits in electronic markets, the reduction in transaction costs may not provide the best measure for these benefits. As argued in the work of Brynjolfsson and Hitt [4] on the "productivity paradox," the metrics based on transaction costs may originate in a market paradigm that is inappropriate for electronic markets. A newer paradigm of customized goods, reduced delivery time, and greater customer satisfaction may be more difficult to measure, but may be the one appropriate to use for electronic markets, as it is in line with the roles of intermediaries in these markets.

Contrary to the predictions of disintermediation, the movement to electronic markets does not seem to result in the elimination of intermediaries, as electronic markets will require intermediation services, albeit in ways that differ from traditional physical markets. Some roles of electronic intermediaries may be similar to the roles of physical intermediaries, while other roles of physical intermediaries may indeed be eliminated in electronic markets, and new roles may emerge for electronic intermediaries.

Finally, it no longer seems appropriate to separate electronic markets into EDI-based and Web/Internet-based electronic commerce. As interoperability between networks, user communities, and standards becomes commonplace, it will provide complementary rather than competing infrastructures.

\section{ACKNOWLEDGMENTS}

We thank Erik Brynjolfsson, David Clark, Eric Clemons and Lee McKnight for useful discussions and ideas that contributed to the insights of this paper. We also thank the students of the electronic commerce class, "15.967: Electronic Commerce/Marketing and the Internet" at the MIT Sloan School of Management for their data collection and insights. Funding has been provided in part by NASA (fellowship NGT-51407), British Telecom and the Center for Information Technology and Organizations at the University of California, Irvine.

\section{REFERENCES}

1. Bakos, Y. Interorganizational information systems: strategic implications for competition and cooperation, Ph.D. thesis, Sloan School of Management, Massachusetts Institute of Technology, 1987.

2. Bakos, Y. Reducing buyer search costs: implications for electronic marketplaces. Management Science, forthcoming (1997). 
3. Bakos, Y. and Brynjolfsson, E. Bundling Information Goods: Pricing, Profits and Efficiency. Working Paper, MIT Center for Coordination Science, December (1996).

4. Brynjolfsson, E. and Hitt, L. Paradox lost? Firm-level evidence on the returns to information systems spending. Management Science, 42, 4, 541-558.

5. Clark, D. D. The design philosophy of the DARPA Internet protocols. Computer Communication Review, 18, 4 (1988), 106-114.

6. Coase, R. H. The nature of the firm. Economica, IV, (1937), 386-405.

7. Clemons, E. K., Reddi, S. P., and Row, M.C. The Impact of Information Technology on the Organization of Economic Activity: The Move to the Middle Hypothesis. Journal of MIS, 10, 2 (1993), 9-35.

8. Demsetz, H. The cost of transacting. Quarterly Journal of Economics, LXXXII (1968), 33-53.

9. Froomkin, A. M. The essential role of trusted third parties in electronic commerce. Oregon Law Review, 75, 1 (1996), 49-116.

10. Gellman, R. Disintermediation and the Internet. Government Information Quarterly, 13, 1 (1996), 1-8.

11. Hirschman, A. O. Exit, Voice, and Loyalty: Responses to Decline in Firms, Organizations, and States. Cambridge, Massachusetts: Harvard University Press, 1970.

12. Kalakota, R., and Whinston, A. B. Frontiers of Electronic Commerce. Reading, Massachusetts: Addison-Wesley, 1996.

13. Malone, T. W., Yates, J., and Benjamin, R. I. Electronic market and electronic hierarchies. Communications of the ACM, 30, 6 (1987), 484-497.

14. Malone, T. W., Yates, J., and Benjamin, R. I. The logic of electronic markets. Harvard Business Review, May-June 1989, 166-170.

15. Resnick, P., Zeckhauser, R., and Avery, C. Roles for electronic brokers. In G. W. Brock (ed.), Toward a Competitive Telecommunication Industry: Selected Papers from the 1994 Telecommunications Policy Research Conference. Mahwah, New Jersey: Lawrence Erlbaum Associates, 1995, 289-306.

16. Treese, W. The Internet index. January, 1996. (http://www.openmarket.com/intindex/ 96-01.htm)

17. Williamson, O. Markets and Hierarchies: Analysis and Antitrust Implications. New York: The Free Press, 1975. 